DOI: $10.4274 /$ tpa.46.24

\title{
Okul çağındaki çocukların sağlık davranışları araşırması
} Health behavior in school-aged children (HBSC) study

\author{
Oya Ercan, Müjgan Alikaşifoğlu, Ethem Erginöz* Ömer Uysal ${ }^{* *}$, Deniz Albayrak Kaymak ${ }^{* * *}$ \\ Istanbul Üniversitesi Cerrahpaşa Tıp Fakültesi, Çocuk Sağlğı ve Hastallkları Anabilim Dall, İstanbul, Türkiye \\ *istanbul Üniversitesi Cerrahpaşa Tıp Fakültesi, Halk Sağı̆̆ı̆ Anabilim Dall, Istanbul, Türkiye \\ **Bezm-i Alem Üniversitesi Tıp Fakültesi, Tıbbi Istatistik ve Tıbbi Bilişim Anabilim Dall, İstanbul, Türkiye

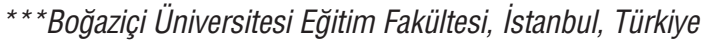

\section{Özet}

Okul Çağındaki Çocukların Sağlık Davranışı "Health Behaviour in School aged Children (HBSC)” çalışması 1983/1984 yılında 5 Avrupa ülkesinde başlatılmış olan, Dünya Sağlık Örgütünün iş birliği ile çok uluslu bir araştırma ekibi tarafından yürütülen ve her 4 yılda bir tekrarlanan kesitsel bir araştırmadır. Son çalışma 2009/2010 yıllarında Türkiye'nin de içinde bulunduğu 43 ülkede gerçekleştirilmiştir. HBSC araştırması yapıldığı ülkelerdeki okul çağı çocuklarının sağlık ve iyilik hallerinin, sağlık davranışlarının ve bu davranışların belirleyicilerinin her ülkede aynı soru formu ile sorgulandığı ayrıntılı bir çalışmadır. Araştırma sonuçları uluslararası ve ulusal raporlar halinde yayınlanmaktadır. Dünya Sağlık Örgütü ve ilgili Birleşmiş Milletler kuruluşları ergenlik çağındaki çocuklarının durumu için bu çalışmanın verilerini kullanmaktadırlar. Türkiye 2005/2006 çalışmasının sonuçlarına örnek vermek gerekirse, öğrencilerin \%30,3'ü sağlıklarının mükemmel, \%51,2'si iyi, \%14,9'u orta ve \%3,6'sı kötü olduğunu bildirilmiştir. Öğrencilerin \%58,4'ü iki ya da daha fazla sağlık yakınmasını haftada birden fazla ya da hemen hemen hergün yaşadığını bildirmiştir. Öğrencilerin sadece \% 30,1'inin yaşam memnuniyeti skoru ortanca değerin üzerinde bulunmuştur. Araştırmanın 2005/2006 uluslararası raporuna göre her iki cinste öğrencilerin yaşamlarından memnun olmaları açısından 41 ülke içinde Türkiye en alt sırada yer almıştır. Yine aynı rapora göre Türkiye'deki öğrenciler dişlerini düzenli olarak fırçalama açısından da en alt sırada yer almışlardır. Araştırma ekibimiz bu çalışmanın ülkemiz ergenlerinin sağlığını desteklemek ve geliştirmek için önemli olduğunu düşünmekte ve çalışmanın kurumsallaşması için uğraş vermektedir. (Türk Ped Arş 2011; 46 Özel Sayı: 15-8)

Anahtar sözcükler: Sağlık, sağlık davranışları, okul çağı çocukları

\section{Summary}

Health Behavior in School-aged Children Study (HBSC) was conducted in five European countries in 1983/1984 for the first time. It is a WHO collaborative cross-sectional study which involves a wide network of multinational researchers. It is repeated every four years. Forty three countries including Turkey participated in the 2009/2010 study. HBSC study is a detailed study that investigates health, well-being and health behaviors of school-aged children and the determinants of these behaviors in all participating countries through the same questionnaire. The results of the study are published both as international and national reports. Related United Nation's Organizations and WHO use the results of this study as indicators of adolescents' health status. According to the Turkish 2005/2006 HBSC study results, $30.3 \%$ of the students reported their health as excellent, $51.2 \%$ as good, $14.9 \%$ as fair and $3.6 \%$ as poor. Fifty nine percent of the students reported that they experience one or more health symptoms more than once a week or almost everyday. Only $30.1 \%$ of the students' life satisfaction scores were above the median value. According to HBSC 2005/2006 study international report, both female and male Turkish students had the lowest life satisfaction scores than those of the other 40 participating countries. Similarly, the ratio of Turkish students who brush their teeth regularly were the lowest among the participating countries. Our national team members believe that this study is important for promoting and improving Turkish adolescents' health and work hard for institutionalization of the study. (Turk Arch Ped 2011; 46 Suppl: 15-8)

Key words: Health, health behavior, school-aged children

Yazışma Adresi/Address for Correspondence: Dr. Oya Ercan,

İstanbul Üniversitesi Cerrahpaşa Tıp Fakültesi Çocuk Sağlığı ve Hastalıkları Anabilim Dalı, İstanbul, Türkiye E-posta: oyaercan@istanbul.edu.tr Türk Pediatri Arşivi Dergisi, Galenos Yayınevi tarafindan basılımıştr. / Turkish Archives of Pediatrics, Published by Galenos Publishing. 


\section{Giriş}

Okul Çağındaki Çocukların Sağlık Davranışı "Health Behaviour in School aged Children (HBSC)" çalışması 1983/1984 yılında 5 Avrupa ülkesinde başlatılımış olan, Dünya Sağlık Örgütünün iş birliği ile çok uluslu bir araştırma ekibi tarafından yürütülen ve her 4 yılda bir tekrarlanan kesitsel bir araştırmadır (1).

\section{HBSC araştırmasının ortaya çıkışı ve büyümesi}

1982 yllında Norveç, Finlandiya ve İngiltere'li araştııııılar ergenlerin sigara içme prevalansının ülkeden ülkeye ne kadar değiştiğini görmek istediklerinde, bu alanda aynı yöntemle toplanmış veriler olmadığından bazı güçlükler yaşadllar. Bu nedenle, ortak bir protokolle yeni bir ülkelerarası araştırma planı oluşturup, karşılaştıılıbilir veriler toplamaya karar verdiler. Öncelikle sigara içme konusunda başlayan bu ortak soru formu giderek ergenlerde sağlıklı yaşam biçimi bağlamında, ergenlerin sağlıkla ilgili riskli davranışlarına doğru evrildi. Danimarka ve Avusturya'dan da araştırıcılar bu ilk gruba katıldılar ve böylece ilk ülkelerarası alan araştırması 5 ülkenin katılıası ile 1983/84 yılında gerçekleştirildi (2).

Belçika'nın Fransızca konuşulan bölümü, Macaristan, İsrail, Hollanda, İskoçya, İsveç ve Galler'in de bu araştırma ağına katılmasıyla 1985/86 yıllarında ikinci araştırma 13 ülkede yapıldı. On yıl içinde HBSC'ye üye ülkeler kurucu 3 ülkeden 25'e yükseldi. 1998 yılında bu sayı 29 oldu (Tablo 1) (1). Çalışma 2009-2010 yilında Türkiye'nin de aralarında olduğu 43 ülkenin katıııılyla gerçekleştirildi (3).

\section{HBSC araştırmasının amaçları ve hedefi}

Bu araștırmanın amaçları:

1- İlgili ülkelerde gençlerin sağlık ve iyilik hallerini korumak, desteklemek ve iyileştirmek yolunda çalışan öğretmenlerin, hekimlerin ve diğer sağlık çalışanlarının okul çağındaki çocukların genel sağlık durumları ve sağlık davranışları hakkında bilgilenmelerini sağlamak;

2- Sağlık politikalarının üretilmesinde söz sahibi olan devlet görevlileri ve kurumları ile politikacılara, okul sağlığı programlarını hazırlayan ve yürüten bakanlık yetkililerine, hazırlayacakları ve geliştirecekleri önleme ve müdahale programlarında yol gösterebilmek;

3- Basın ve yayın organları aracıı̆ı̆ı ile halkın bilgilenmesini sağlamak ve akademik dünya ile günümüz gençliğine ait verileri paylaşıp tartışmaktır $(1,2)$.

Böylece Dünya Sağlık Örgütü Avrupa Bölgesi ve Kuzey Amerika'da ergen sağlığını koruma, destekleme ve geliştirme çalışmalarına katkıda bulunmak hedeflenmektedir.

\section{HBSC araștırmasının ilgi alanları}

HBSC araştırmasının uluslar arası araştırma ekibi Dünya Sağlık Örgütü'nün sağlığı sadece hastalıkların olmaması hali olarak değil, fiziksel, sosyal ve ruhsal tam bir iyilik hali olarak kabul eden görüşünü benimsemiştir (1). Bu nedenle sağlık günlük yaşam için bir kaynak olarak görülür ve bu nedenle:

- Sadece gençlerin sağlık ve sağlık davranışlarının zaman içerisinde ve ülkeden ülkeye nasıl değiştiği ile ilgilenilmez, ayrıca mahalle, okul, aile, arkadaşlar ve sosyoekonomik çevre gibi ergenlerin şekillendikleri ortamların onların sağlık ve sağlık davranışlarını nasıl şekillendirdiği ve etkilediği ile de ilgilenir.

- Fiziksel, duygusal ve toplumsal sağlık ve esenliği değerlendirir.

- Sağlığı geliştirici ve riske atıcı davranışları ölçer.

- Gençlerin sağlık davranışlarını gelişimsel ve sosyal bağlamda anlamaya çalışır.

HBSC araştırmasının soru formunda 2 ana başlık altında toplanan aşağıdaki alanlara yönelik sorular yer almaktadır $(1,2)$ :

Sağlık ve Davranış

- Algılanan sağlık, esenlik ve yaşam memnuniyeti

- Sigara, alkol ve uyuşturucu

- Fiziksel aktivite ve sedanter davranıșlar

- Beslenme

- Beden algisı

- Boy ve kilo

- Cinsel davranışlar

- Zorbalık ve kavga

- Yaralanmalar

Sosyal ve gelişimsel bağlam

- Aile yapısı ve ilişkileri

- Okul ortamı

- Arkadaş ilişkileri ve sosyal davranışlar

- Sosyoekonomik koșullar (aile, yaşanılan çevre)

- Cinsel gelişim

$\mathrm{Bu}$ alanlardaki soruların bir kısmı tüm ülkelerce sorulması beklenen zorunlu sorulardır, bir kısmı ise kullanımı ülkelerin tercihine bırakılmış seçmeli sorulardır (1).

\section{HBSC araștırmasına bir örnek: Türkiye modeli}

HBSC 2005/2006 araștırmasının Türkiye ayağının yöntemi ve sonuçları "Okul Çağı Çocuklarının Sağlık Davranışı Araştırması Türkiye 2006 Raporu" adlı raporda ayrıntılı olarak sunulmuştur (4).

Türkiye örneklemi katmanlı küme yöntemi ile belirlenmiştir. Örneklem birimi okuldur. Araştırmaya 12 NUTS 1 bölgesinden tesadüfen belirlenen 26 ilden, 165 okuldaki 268 derslikte 8675 öğrenci katılmıștır. Ülkemiz verileri araștırmaya uygun yaş grubunda bulunan 5552 öğrenci üzerinden değerlendirilmiştir (4). 
Ülkemizde araştırmanın uygulama evresi sınıf ortamında ve öğretmenlerinin gözetiminde yapılmaktadır. Anonimliği sağlamak için her öğrenciye bir zarf verilmekte ve öğrenci soru formunu bitirdiğinde kendisine ait zarfa koyarak öğretmene teslim etmesi istenmektedir.

Milli Eğitim Bakanlığı tarafından sigara, alkol, madde kullanımı ve cinsel sağlıkla ilgili zorunlu soruların sorulması onaylanmamıştır. Araştırmanın ana konu başlıklarına ait temel sonuçlar aşağıda sıralanmıştır.

\section{Sağlık ve Davranış}

Öğrencilerin \%30,3'ü ( $n=1669)$ sağlıklarının mükemmel, \%51,2'si ( $n=2821)$ iyi, \%14,9'u ( $n=821)$ orta ve \%3,6'sı ( $n=199)$ kötü olduğunu bildirdi (4).

Öğrencilerin \%58,4'ü iki ya da daha fazla sağlık yakınmasını (Baş ağıısı, karın ağrısı, sııt ağısı, moral bozukluğu, çabuk sinirlenmek ya da huysuzluk, gerginlik ya da kaygı hissi, uyuma güçlüğü ve baş dönmesi) haftada birden fazla ya da hemen hemen hergün yaşadığını bildirdi (4).

\section{Tablo 1. Bugüne Kadar Yapılan HBSC Araştırmaları ve Katılan Ülkeler (1)}

\begin{tabular}{|c|c|c|c|c|c|c|}
\hline 1983-84 & 1985-86 & $1989 / 1990$ & $1993 / 1994$ & 1997/1998 & 2001/2002 & $2005 / 2006$ \\
\hline $\begin{array}{l}\text { 1.Ingiltere } \\
\text { 2. Finlandiya } \\
\text { 3. Norveç } \\
\text { 4. Avusturya } \\
\text { 5. Danimarka }\end{array}$ & $\begin{array}{l}\text { 1.Finlandiya } \\
\text { 2. Norveç } \\
\text { 3. Avusturya } \\
\text { 4. Danimarka } \\
\text { 5. Belçika } \\
\text { 6. Macaristan } \\
\text { 7. İsrail } \\
\text { 8. İskoçya } \\
\text { 9. İspanya } \\
\text { 10. İsveç } \\
\text { 11. İsviçre } \\
\text { 12. Galler } \\
\text { 13. Hollanda }\end{array}$ & $\begin{array}{l}\text { 1.Finlandiya } \\
\text { 2. Norveç } \\
\text { 3. Avusturya } \\
\text { 4. Danimarka } \\
\text { 5. Belçika } \\
\text { 6. Macaristan } \\
\text { 7. İskoçya } \\
\text { 8. İspanya } \\
\text { 9. İsveç } \\
\text { 10. İsviçre } \\
\text { 11. Galler } \\
\text { 12. Hollanda } \\
\text { 13. Kanada } \\
\text { 14. Letonya } \\
\text { 15. K. Irlanda } \\
\text { 16. Polanya }\end{array}$ & $\begin{array}{l}\text { 1. Finlandiya } \\
\text { 2. Norveç } \\
\text { 3. Avusturya } \\
\text { 4.Belçika (Fr) } \\
\text { 5. Macaristan } \\
\text { 6. Israil } \\
\text { 7. İskoçya } \\
\text { 8. İspanya } \\
\text { 9. İsveç } \\
\text { 10. İsviçre } \\
\text { 11. Galler } \\
\text { 12. Danimarka } \\
\text { 13. Kanada } \\
\text { 14. Letonya } \\
\text { 15. K.İlanda } \\
\text { 16. Polanya } \\
\text { 17.Belçika (FI) } \\
\text { 18.Çekya } \\
\text { 19. Estonya } \\
\text { 20. Fransa } \\
\text { 21. Almanya } \\
\text { 22. Grönland } \\
\text { 23. Litvanya } \\
\text { 24. Rusya } \\
\text { 25. Slovakya }\end{array}$ & $\begin{array}{l}\text { 1. Finlandiya } \\
\text { 2. Norveç } \\
\text { 3. Avusturya } \\
\text { 4.Belçika (Fr) } \\
\text { 5. Macaristan } \\
\text { 6. İsrail } \\
\text { 7. İskoçya } \\
\text { 8. İsveç } \\
\text { 9. İsviçre } \\
\text { 10. Galler } \\
\text { 11. Danimarka } \\
\text { 12. Kanada } \\
\text { 13. Letonya } \\
\text { 14. K. Irlanda } \\
\text { 15. Polanya } \\
\text { 16. Belçika(Fl) } \\
\text { 17.Çekya } \\
\text { 18. Estonya } \\
\text { 19. Fransa } \\
\text { 20. Almanya } \\
\text { 21. Grönland } \\
\text { 22. Litvanya } \\
\text { 23. Rusya } \\
\text { 24. Slovakya } \\
\text { 25. İngiltere } \\
\text { 26. Yunanistan } \\
\text { 27. Portekiz } \\
\text { 28. Irlanda } \\
\text { 29. ABD }\end{array}$ & $\begin{array}{l}\text { 1. Finlandiya } \\
\text { 2. Norveç } \\
\text { 3. Avusturya } \\
\text { 4.Belçika (Fr) } \\
\text { 5. Macaristan } \\
\text { 6. İsrail } \\
\text { 7. İskoçya } \\
\text { 8. İspanya } \\
\text { 9. İsveç } \\
\text { 10. İsviçre } \\
\text { 11. Galler } \\
\text { 12. Danimarka } \\
\text { 13. Kanada } \\
\text { 14. Letonya } \\
\text { 15. Polanya } \\
\text { 16.Belçika (Fl) } \\
\text { 17.Çekya } \\
\text { 18. Estonya } \\
\text { 19. Fransa } \\
\text { 20. Almanya } \\
\text { 21. Grönland } \\
\text { 22. Litvanya } \\
\text { 23. Rusya } \\
\text { 24. İngiltere } \\
\text { 25. Yunanistan } \\
\text { 26. Portekiz } \\
\text { 27. Irlanda } \\
\text { 28. ABD } \\
\text { 29. Makedonya } \\
\text { 30. Hollanda } \\
\text { 31. Italya } \\
\text { 32. Hırvatistan } \\
\text { 33. Malta } \\
\text { 34. Slovenya } \\
\text { 35. Ukrayna }\end{array}$ & $\begin{array}{l}\text { 1. Finlandiya } \\
\text { 2. Norveç } \\
\text { 3. Avusturya } \\
\text { 4.Belçika (Fr) } \\
\text { 5. Macaristan } \\
\text { 6. İsrail } \\
\text { 7. İskoçya } \\
\text { 8. İspanya } \\
\text { 9. İsveç } \\
\text { 10. İsviçre } \\
\text { 11. Galler } \\
\text { 12. Danimarka } \\
\text { 13. Kanada } \\
\text { 14. Letonya } \\
\text { 15. Polanya } \\
\text { 16. Belçika (FI) } \\
\text { 17.Çekya } \\
\text { 18. Estonya } \\
\text { 19. Fransa } \\
\text { 20. Almanya } \\
\text { 21. Grönland } \\
\text { 22. Litvanya } \\
\text { 23. Rusya } \\
\text { 24. İngiltere } \\
\text { 25. Yunanistan } \\
\text { 26. Portekiz } \\
\text { 27. Irlanda } \\
\text { 28. ABD } \\
\text { 29. Makedonya } \\
\text { 30. Hollanda } \\
\text { 31. Italya } \\
\text { 32. Hırvatistan } \\
\text { 33. Malta } \\
\text { 34. Slovenya } \\
\text { 35. Ukrayna } \\
\text { 36. Lükseemburg } \\
\text { 37. Türkiye } \\
\text { 38. Slovakya } \\
\text { 39. Romanya } \\
\text { 40. Izlanda } \\
\text { 41. Bulgaristan }\end{array}$ \\
\hline
\end{tabular}


Öğrencilerin \%30,1'inin ( $n=1847)$ yaşam memnuniyeti skoru ortanca değerin altında idi.

Öğrencilerin \%7,2'si son bir hafta içinde hiç orta-ağır fiziksel etkinlikte bulunmadıklarını bildirirken, \%25,7'si en az 6 gün günde en az 60 dakika fiziksel etkinlikte bulunduğunu bildirdi (4).

Öğrencilerin \%64'ü hafta içinde günde en az iki saat televizyon (VCD-DVD) izliyordu.

Öğrencilerin \%25,7'si hafta içi günde en az iki saat, \%14,9'u hafta içinde günde en az üç saat bilgisayar ya da oyun aletlerinde oyun oynuyordu (4).

Öğrencilerin \%60,5'i ( $n=3241)$ hafta içi hergün kahvaltı ettiğini, \%39,5'i ( $n=2112)$ ise hafta içi hergün kahvaltı etmediğini bildirdi (4).

Öğrencilerin \%36,8'i ( $n=1996)$ günde en az bir kere meyve yediğini, \%63,2'si ise $(n=3424)$ hergün meyve yemediğini bildirdi (4).

Öğrencilerin \%26,4'ü ( $n=1413)$ günde en az bir kere sebze yediğini, \%73,6'sı ise $(n=3941)$ hergün sebze yemediğini bildirdi (4).

Öğrencilerin \%27,3'ü $(n=1462)$ günde en az bir kere şeker ya da çikolata yediğini, \%72,7'si ise $(n=3903)$ hergün şeker ya da çikolata yemediğini bildirdi (4).

Öğrencilerin \%19,7'si ( $n=1059)$ günde en az bir kere şeker içeren kola ya da diğer gazlı içecekleri içtiğini, $\% 80,3$ 'ü ise $(n=4321)$ hergün şeker içeren kola ya da diğer gazlı içecekleri içmediğini bildirdi (4).

Öğrencilerin \%34,6'sı $(n=1919)$ günde bir kereden fazla diş fırçaladıklarını belirttiler.

Öğrencilerin çoğunluğu $(\% 65,2)$ son $1-2$ ay içerisinde zorbalığa uğradıklarını, \%15,8'i $(n=841)$ ise haftada en az bir kere zorbalığa uğradıklarını belirttiler (4).

Öğrencilerin \%40,7'si son 1-2 ay içerisinde en az bir kere, \%9'u $(n=476)$ ise haftada en az bir kere diğer öğrencilere zorbalık yaptıklarını belirttiler (4).

Öğrencilerin \%53,3'ü $(n=2536)$ son 12 ay içinde en az bir kere dövüşe karışıtıklarını belirttiler (4).

Öğrencilerin \%40,2'si ( $n=2181)$ son 12 ay içinde en az bir kere yaralandığını bildirdi (4).

\section{Sosyal ve gelişimsel bağlam}

Öğrencilerin \%69,6'sının aile refah düzeyi düşük, $\% 25$ 'inin orta ve \%5,4'ünün yüksekti. Türkiye'deki ergenlerin \%85,2'si her iki ebeveyni ile birlikte, \%10,5'i ebeveynlerinden biri ile ve \%1,2'si üvey anne ya da baba ile yaşadığını bildirdi (4).

Babaları ile canlarını gerçekten sıkan şeyler hakkında konuşmayı öğrencilerin \%21,3'ü $(n=1049)$ çok kolay, \%30'u $(n=1475)$ kolay, \%27,6'sı $(n=1360)$ zor ve \%14,8'i $(n=729)$ çok zor bulduklarını belirttiler. Öğrencilerin \%6,2'sinin $(\mathrm{n}=306)$ babası yoktu ya da babasını görmüyordu (4).

Anneleri ile canlarını gerçekten sıkan şeyler hakkında konuşmayı öğrencilerin \%46,6'ı $(n=2267)$ çok kolay, \%34,3'ü $(n=1667)$ kolay, \%10,7'si $(n=520)$ zor ve \% 5,3'ü $(n=256)$ çok zor bulduklarını belirttiler. Öğrencilerin $\% 3,2$ 'sinin ( $n=156$ ) annesi yoktu ya da onu görmüyordu (4).

En iyi arkadașları ile canlarını gerçekten sıkan șeyler hakkında konuşmayı öğrencilerin \%60,7'si $(n=2965)$ çok kolay, \%29,1'i $(n=1422)$ kolay, \%5,9'u ( $n=288)$ zor ve \%2,1'i
( $n=101$ ) çok zor bulduklarını belirttiler. Öğrencilerin \%2,2'sinin $(n=105)$ en iyi arkadaşı yoktu ya da onu görmüyordu (4).

Öğrencilerin \%57,3'ü (n=3166) okulu çok sevdiğini, \%30,8'i ( $n=1701)$ biraz sevdiğini, \%7,3'ü $(n=406)$ çok sevmediğini, \%4,6'sı ( $\mathrm{n}=252$ ) hiç sevmediğini bildirdi (4).

Türkiye 2005/2006 araştırmasının bazı çarpıcı sonuçlarının diğer ülkelerin sonuçları ile karșılaștırılması

On beş yaş grubunda anneyle konuşmayı kolay bulma açısından hem kızlarda hem de erkeklerde $\% 80$ oranı ile Türkiye 14. sırada yer alırken, aynı yaş grubunda baba ile konuşmayı kolay bulma açısından kızlarda \%45, erkeklerde $\% 50$ oranıyla alttan 7 . sırada yer aldı (1).

Yine 15 yaş grubunda arkadaşlarla elektronik medya araçları ile iletişimde kızlarda \%38, erkeklerde ise \%22 oranıyla en alt sırada yer aldı (1).

Türkiye 13 yaș grubunda okulu sevme açısından kızlarda $\% 66$ erkeklerde $\% 50$ oranıly 1 . sırada yer aldı.

On bir (kızlar:\%41, erkekler:\%49) ve 13 (kızlar:\%59, erkekler:\%61) yaş gruplarında, okul ödevleri ve derslerden dolayı baskı hissetme açısından Türkiye 1. sırada yer aldı (1).

On bir (kılar:\%73, erkekler:\%78), 13 (kılar:\%63, erkekler:\%69) ve 15 yaş (kızlar:\%61, erkekler:\%64) gruplarında öğrencilerin yaşamlarından memnun olmaları açısından Türkiye en alt sırada yer aldı (1).

On üç yaş grubunda günde bir kereden fazla diş fırçalama sıklığı açısından kızlarda \%37, erkeklerde \%22 oranları ile Türkiye en alt sırada yer aldı (1).

\section{Sonuç}

HBSC araştırması yapıldığı ülkelerdeki okul çağı çocuklarının sağlık ve iyilik hallerini ve sağlık davranışlarını ve bu davranışların belirleyicilerini sorgulayan ayrıntılı bir çalışmadır. Araştırma sonuçları uluslararası ve ulusal raporlar halinde yayınlanmaktadır. Dünya Sağlık Örgütü ve ilgili Birleşmiş Milletler kuruluşları ergenlik çağındaki çocuklarının durumu için bu çalışmanın verilerini kullanmaktadırlar.

Araştırma ekibimiz bu çalışmanın ülkemiz ergenlerinin sağlığını desteklemek ve geliştirmek için önemli olduğunu düşünmekte ve çalışmanın kurumsallaşması için uğraş vermektedir.

\section{Kaynaklar}

1. Inequalities in young people's health. Health Behaviour in School-aged Children International Report from the 2005/2006 survey World Health Organization 2008. (Abstract)

2. Currie C, Gabhainn SN, Godeau E and the International HBSC Network Coordinating Committee. The Health Behaviour in School-aged Children: WHO Collaborative Cross-National (HBSC) Study: origins, concept, history and development 1982-2008. Int J Public Health 2009; 54: 131-9. (Abstract)

3. Health Behaviour in School-aged Children. Participating country 2010. http://www.hbsc.org/countries.html (erişim tarihi 28.08.2010) (Abstract)

4. Ercan O, Alikaşifoğlu M, Erginöz E, Kaymak DA, Uysal Ö (eds.). Okul Çağı Çocuklarının Sağlık Davranışı Araştırması Türkiye 2006 Raporu. İstanbul; Galenos yayınevi, 2009. 